\title{
Evaluation of Material Data to the Numerical Strain-Life Analysis of the Compressor Blade Subjected to Resonance Vibrations
}

\author{
Arkadiusz Bednarz' \\ 1 Rzeszow University of Technology, Al. Powstancow Warszawy 8, 35-959 Rzeszow, Poland \\ e-mail: abednarz@prz.edu.pl
}

\begin{abstract}
This paper presents the impact of selecting the fatigue material model on the numerically determined fatigue life of a compressor blade. In the work, the first stage compressor blade of the PZL-10W turbine engine was used. The research object contained a geometric notch with a known location and shape. In numerical studies, 8 fatigue estimation methods were used in the $\varepsilon-\mathrm{N}$ analysis (based on the Manson-Coffin-Basquin model). At the same time, three methods for estimating material constants associated with the cyclic hardening were employed. On the basis of the selected models, 24 sets of fatigue parameters were obtained, which were used in numerical studies. The numerical tests were carried out under resonant conditions with amplitudes of 1.5 and $1.8 \mathrm{~mm}$. The numerical tests were confirmed by the experimental fatigue tests. As a result of the above-mentioned tests, the impact of selecting the material fatigue model and hardening model on the obtained results was determined and they were referred to the initiation of the crack with the length $\mathrm{a}=0.2 \mathrm{~mm}$ (achieved during experimental studies). The obtained results will constitute the basis for further fatigue tests.
\end{abstract}

Keywords: fatigue life, crack initiation, vibrations, strain-life, compressor blade, strain hardening

\section{INTRODUCTION}

Compressor blades are used as critical elements of the aircraft engine. This naming is connected to geometry, work conditions, and potential failures [5]. The blades from the first stage of the compressor are thin in comparison to the rest of the geometrical parameters [4]. This feature makes the blade susceptible to resonant bending. In the case of the existing mechanical vibrations, resonance may occur. The worst scenario is when on a notch or crack is observed on the leading edge [14]. The notch may occur when a hard object (like stone i.e.) is sucked into the engine and hits the blade. On the other hand, the forces caused by airflow and centrifugal forces connected to high rotational velocity act on the blade. Additionally, because of the weight of the aircraft, the blade is usually made of special high-strength alloys with lower density and is exposed to special treatment. This treatment, such as shot peening or layering, may increase the local strength and resistance to the fatigue crack initiation. In the aviation technology, laminates and composite materials also appear increasingly often [8, 12]. However, due to the fact that plastic deformation and cyclic strengthening are not observed in composite materials, the fatigue equations presented in this paper should not be used in the analysis of the components made with composite techniques.

The failures and fatigue fractures connected to low cycle fatigue (LCF) are extremely dangerous. Every engine has its own special plan of inspection to prevent any failures. In the case of resonance and notch, in order to high deformation and strains made by bending, theoretically a situation when notch will be formed and crack will start to propagate between two next inspections may happen. Low Cycle Fatigue is directly connected to high values of strains (elastic and plastic strain) [11]. In the literature, connecting the LCF [2, 15] with a Strain-Life numerical analysis is popular. In analytical and numerical 
way, the Manson-Coffin-Basquin [3, 7] equation is used in order to estimate the number of load cycles till cracks initiate. Unfortunately, these relations and models are usually good for the simple shape of specimens, in a simple case of the load case, but not quite good for the elements with complex geometry and complex load scenario. Because of this, it is necessary to obtain the information on how the material fatigue [9, 11] model impacts the results of the numerical fatigue analysis for the specimens with complex geometry $[13,14]$. The blade may be a good example of that type of geometry.

The main purpose of this work was to determine the relationship between the material fatigue model and a number of load cycles until crack initiation in the case of the blade with the notch. Numerical estimations of the fatigue life were compared with the experimental results. The conducted considerations can serve as a hint as to which material model to use for an element with complex geometry and a complex state of the load. The obtained results have both a theoretical and practical value.

\section{STRAIN-LIFE MATERIAL DATA}

As mentioned, the Low Cycle Fatigue is determined by Strain-Life $(\varepsilon-\mathrm{N})$ analysis. In order to conduct the $\varepsilon-\mathrm{N}$ analysis which is based on the Manson-Coffin-Basquin (MCB) equation (eq. 1), it is necessary to estimate the material data. The $\mathrm{MCB}$ equation is based on the relation between strain amplitude and two fatigue components. Total strain amplitude $\frac{\Delta \varepsilon}{2}$ is obtained from an arithmetic average of the elastic and plastic strain

$$
\frac{\Delta \varepsilon}{2}=\frac{\varepsilon_{e}+\varepsilon_{p}}{2}=\frac{\sigma_{f}{ }^{\prime}}{E}(2 N)^{b}+\varepsilon_{f}{ }^{\prime}(2 N)^{c}
$$

where: $\frac{\Delta \varepsilon}{2}-$ total strain amplitude $\varepsilon_{\mathrm{e}}-$ elastic strain

$\varepsilon_{\mathrm{p}}$ - plastic strain

$\Delta \sigma-2 \cdot$ the stress amplitude, MPa

$\mathrm{E}$ - Young modulus, $\mathrm{MPa}$

$\mathrm{N}$ - number of cycles to failure

$2 \mathrm{~N}$ - number of reversals to failure

$\sigma_{f}{ }^{\prime}$ - fatigue strength coefficient

$\mathrm{b}$ - fatigue strength exponent (Basquin

Exponent)

$\varepsilon_{f}^{\prime}-$ fatigue ductility coefficient

$\mathrm{c}$ - fatigue ductility exponent

The examined blade of the first stage compressor from the PZL-10W turbine engine is made of the EI-961 chromium alloy (GOST: 13H12N2V2MF). Eight different material fatigue models were used in the presented work: Manson, 4-point Manson, Mitchell, Muralidharan-Manson, Baumel-Seeger, Ong, Roessle-Fatemi and Median. The equations used to estimate the material data for each model were taken from literature. Each model is based on the tensile properties of the alloy or a fixed value. The estimated values of this material data were presented in Table 1 .

The material data for the MCB fatigue models (from Table 1) allow creating an MCB curve for every material model of the EI-961 alloy. These curves were shown in Figure 1.

The highest value of $\sigma_{f}{ }^{\prime}$ is observed for the Manson model (2280 MPa), while the lowest for the Ong model. In the case of $\varepsilon_{f}{ }^{\prime}$, the highest value is also observed for Manson model, while the lowest value for the Mitchell and Roessle-Fatemi models (0.12). In the case of the fatigue strength exponent, the highest value is observed for the Manson model. In this model, the value of "b" is assumed in advance (not calculated). The lowest "b" value was obtained for the Ong model. In the case of fatigue ductility exponent, the highest value is observed for the Manson and Mitchell model, and the lowest value for the Ong model. The fatigue strength exponent and fatigue

Table 1. Fatigue models of material

\begin{tabular}{|c|c|c|c|c|c|}
\hline Fatigue model of material & Shortcut name & $\sigma_{\mathrm{f}}^{\prime}, \mathrm{MPa}$ & $\varepsilon_{\mathrm{f}}^{\prime}$ & $b$ & C \\
\hline Manson (1965) & Man & 2280 & 0.60997 & -0.12 & -0.6 \\
\hline 4 point Manson (1965) & Man4 & 1172.23 & 0.52793 & -0.064 & -0.573 \\
\hline Mitchell (1977) & Mit & 1545 & 0.12 & -0.068 & -0.6 \\
\hline Muralidharan-Manson (1988) & MM & 1765.79 & 0.27872 & -0.09 & -0.56 \\
\hline Baumel-Seeger (1990) & BS & 1800 & 0.368 & -0.087 & -0.58 \\
\hline Ong (1993) & Ong & 1344 & 0.12 & -0.047 & -0.481 \\
\hline Roessle-Fatemi (2000) & RF & 1508.5 & 0.13953 & -0.09 & -0.56 \\
\hline Median (2002) & Med & 1800 & 0.45 & -0.09 & -0.59 \\
\hline
\end{tabular}




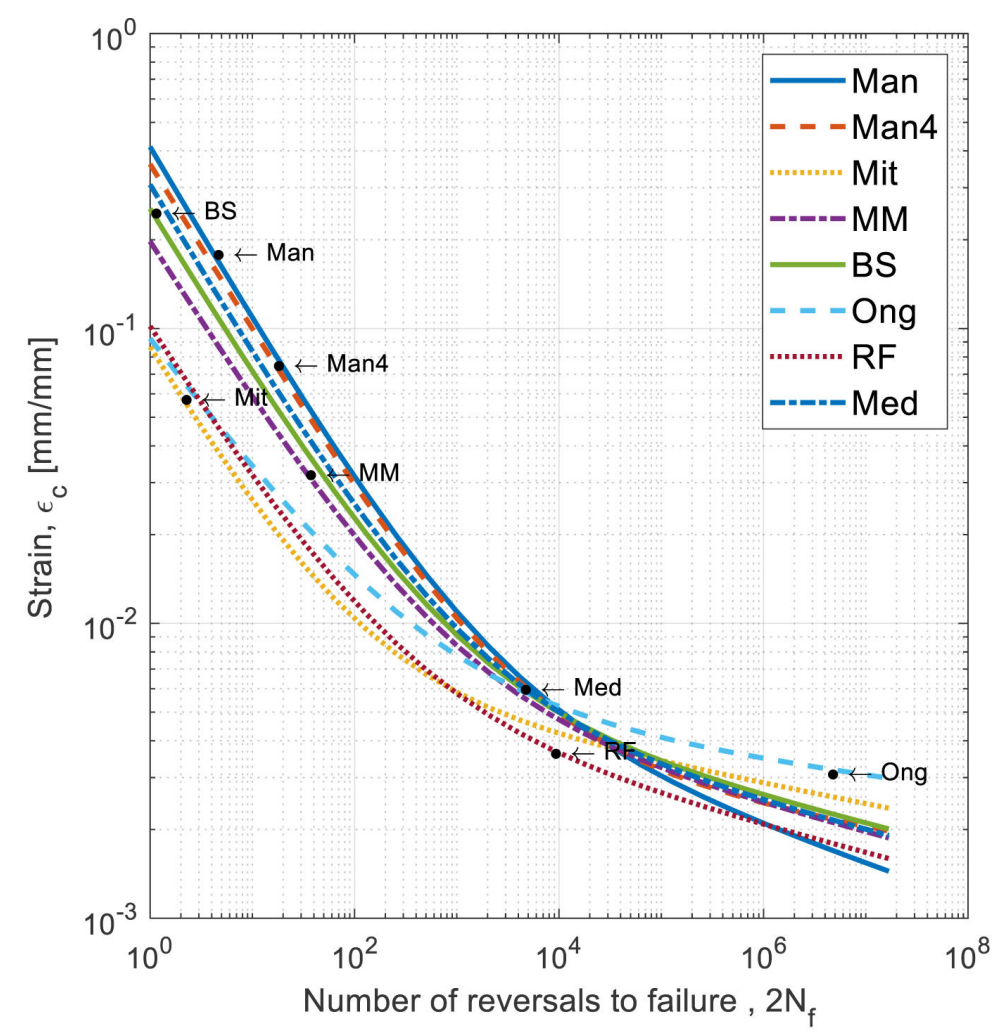

Fig. 1. Manson-Coffin-Basquin curves for a different material model of EI-961 alloy

ductility exponent value define the rate of deformation change (tangent of the curve slope) on the Manson-Coffin-Basquin chart.

Due to the fact that steels (and alloys) exhibit the phenomenon of strain hardening due to loading, the material model proposed by Ramberg-Osgood (RO) - eq. 2, developed for the curve of cyclic hardening $\left(\sigma-\varepsilon_{\alpha}\right)$ is used for the calculation of strain based on stress:

$$
\Delta \varepsilon=\frac{\Delta \sigma}{E}+2\left(\frac{\Delta \sigma}{2 K^{\prime}}\right)^{1 / n^{\prime}}
$$

where: $\mathrm{K}^{\prime}$ - cyclic strength coefficient, MPa

$\mathrm{n}^{\prime}$ - cyclic strain hardening exponent

In this paper, three different models of cyclic hardening were used. The most common is Manson hardening (for Ramberg-Osgood equation). It assumes that the cyclic strain hardening exponent is constant for every material model. Other hardening models like Fatemi and Xianxin are more complex. The cyclic hardening coefficient and exponent for different fatigue material models (of MCB) were shown in Table 2.

On the basis of the data above (Table 3), the diagram in Figure 2 was drawn. The closest to the tensile test curve is the curve determined based on the Fatemi model. The other two curves, in the observed deformation range from 0 to $0.05 \mathrm{~mm} / \mathrm{mm}$, are characterized by a large divergence. At the same time, observing the trends of changes taking place in Figure 2, it can be assumed that for the deformations above $0.04 \mathrm{~mm} / \mathrm{mm}$, the Manson model will be closer to the tensile curve. The Xianxin model in the whole range is far from the tensile curve.

\section{NUMERICAL FATIGUE ANALYSIS}

\section{Basic assumptions of the analysis}

The fatigue constants determined and presented in the second chapter, as well as the quantities defining cyclic hardening, were used to create the paddle fatigue numerical analysis during resonance vibrations. This analysis has several stages. In the first stage, the resonance state (with a given amplitude) and the corresponding stress and strain values were achieved. Then, for dynamic results, the fatigue analyses were carried out. The same geometrical model of the blade was used in all numerical analyses. This model is a blade of the first stage of the PZL-10W turbine helicopter engine. The material model built on Young modulus (linear elastic model) was used in 
Table 2. Hardening models data

\begin{tabular}{|c|c|c|c|c|c|c|}
\hline Fatigue model of material & $\mathrm{K}_{1}^{\prime}$ & $\mathrm{n}_{1}^{\prime}$ & $\mathrm{K}_{2}^{\prime}$ & $\mathrm{n}_{2}^{\prime}$ & $\mathrm{K}_{3}^{\prime}$ & $\mathrm{n}_{3}^{\prime}$ \\
\hline Man & 2516.94 & \multirow{8}{*}{0.2} & 2516.94 & 0.2 & \multirow{8}{*}{1775.535} & \multirow{8}{*}{0.1665} \\
\hline Man4 & 1331.98 & & 1258.31 & 0.1109 & & \\
\hline Mit & 2360.98 & & 1967.88 & 0.1141 & & \\
\hline MM & 2279.85 & & 2168.25 & 0.1607 & & \\
\hline BS & 2198.38 & & 2091.2 & 0.15 & & \\
\hline Ong & 2053.82 & & 1656.08 & 0.0985 & & \\
\hline RF & 2236.73 & & 2070.19 & 0.1607 & & \\
\hline \multirow[t]{2}{*}{ Med } & 2111.69 & & 2033.16 & 0.1525 & & \\
\hline & \multicolumn{2}{|c|}{ Manson method } & \multicolumn{2}{|c|}{ Fatemi method } & \multicolumn{2}{|c|}{ Xianxin method } \\
\hline
\end{tabular}

the numerical analysis. The use of such a model has simplified and shortened the time of analysis. The numerical analyses performed based on the finite element method were conducted using commercial ANSYS software [1].

\section{Analysis preparation and numerical simulations}

The geometric model of a notched blade was digitized using tetrahedral elements (with square shape functions). In addition, a discrete mesh was compacted around the notch bottom to increase the resolution of the results obtained and to achieve greater accuracy. The element size was selected by iterative reduction of the element size until the difference in equivalent stress was obtained on the assumed level (difference below $0.1 \mathrm{MPa})$.
The geometric model of the blade contained a geometric notch, located on the leading edge, $3 \mathrm{~mm}$ from the blade foot. This notch was $\mathrm{V}$-shaped and $0.5 \mathrm{~mm}$ deep. The rounding radius at the bottom of the notch was $0.05 \mathrm{~mm}$. The notch dimensions were chosen so that they correspond to the notch dimensions from the experimental studies.

As a result of the numerical modal analysis, the distribution of the equivalent stress $\sigma_{\text {eqv }}$ (Figure 3) and the principal stress $\sigma_{1}$ was determined for two values of the amplitude of resonance vibrations $-\mathrm{A}=1.5 \mathrm{~mm}$ and $\mathrm{A}=1.8 \mathrm{~mm}$. The identical location of the maximum stress value was observed in both amplitude variants. The largest value of the equivalent stress was observed at the bottom of the notch, at a distance of about $0.2 \mathrm{~mm}$ from the inner side of the blade. The first mode of resonance vibrations is a bending form and occurs at a frequency of $789 \mathrm{~Hz}$.

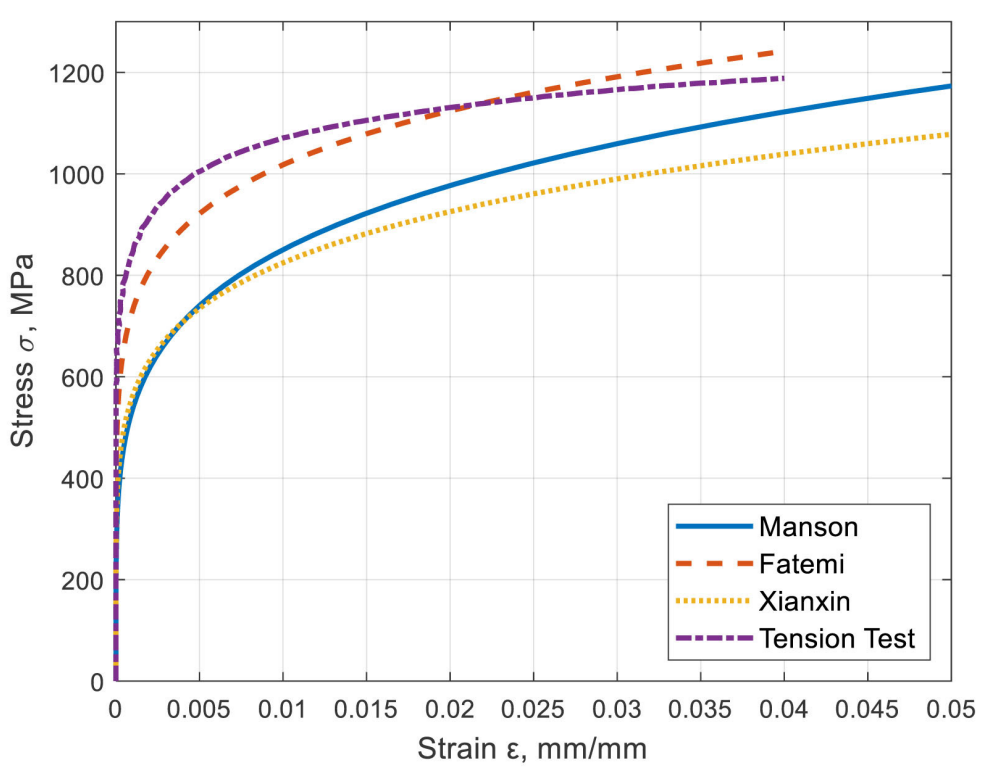

Fig. 2. Experimental and analytical hardening curves for the EI-961 alloy steel 


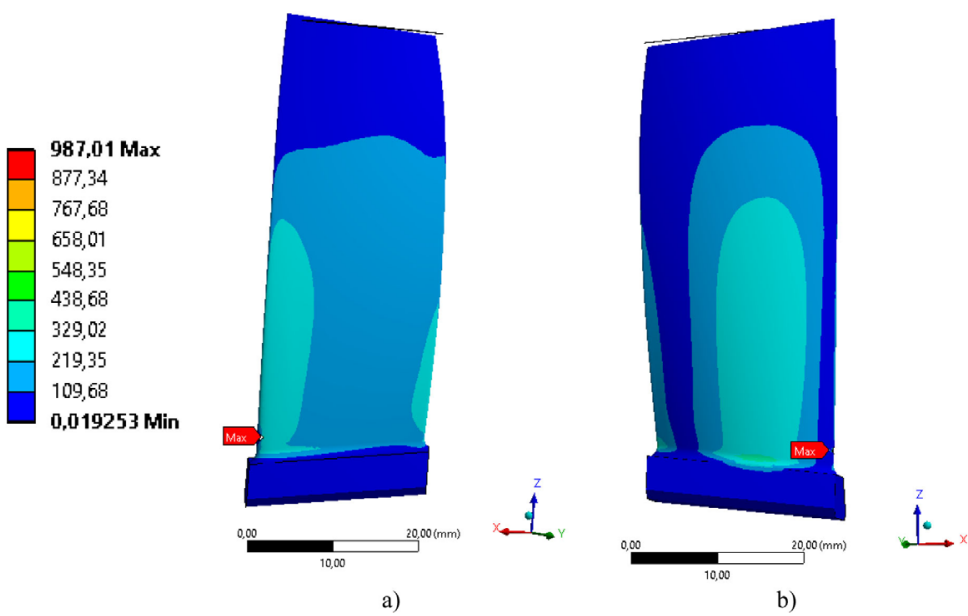

Fig. 3. Distribution of the equivalent stress on both the internal (a) and external (b) surfaces of the analyzed compressor blade, under resonance with an amplitude of $\mathrm{A}=1.8 \mathrm{~mm}$

In the case of resonance vibration with an amplitude of $\mathrm{A}=1.8 \mathrm{~mm}$, the maximum value of equivalent stress (determined by the Huber-Mises-Hencky hypothesis) was $\sigma_{\text {eqv }}=987 \mathrm{MPa}$ (Figure $4 \mathrm{a}$ ). The maximum value of the principal stress was $\sigma_{1}=1171 \mathrm{MPa}$ (Figure $4 \mathrm{~b}$ ). In the case of resonance with an amplitude of $\mathrm{A}=1.5 \mathrm{~mm}$, the stress values were: $\sigma_{\text {eqv }}=822 \mathrm{MPa}$ and $\sigma_{1}=976 \mathrm{MPa}$, respectively.

\section{RESULTS OF NUMERICAL FATIGUE ANALYSIS}

The obtained values of the principal stresses were used to conduct the numerical fatigue analysis. The obtained material models (eight models - Table 1) and hardening models (3 models - Table 2) created 24 data configurations for $\varepsilon-\mathrm{N}$ numerical fatigue analysis. The results of the discussed analyses are presented in Table 3. Additionally, three values were determined, i.e. the maximum, average and minimum value of the number of cycles for the crack initiation.

Firstly, the results of numerical fatigue analysis of a compressor blade working under the conditions of resonance vibrations with an amplitude of $1.5 \mathrm{~mm}$ were discussed. The highest number of load cycles for crack initiation is observed when using the Ong model with Fatemi hardening and was Nin $=54.72 \cdot 10^{3}$. The lowest number of load cycles for crack initiation was $\mathrm{Nin}=1.43 \cdot 10^{3}$ and is observed for the Roessle-Fatemi model Xianxin hardening. The average value in the case of resonance with a vibration amplitude of the tip of the blade $\mathrm{A}=1.5 \mathrm{~mm}$, is equal to $9.04 \cdot 10^{3}$. The

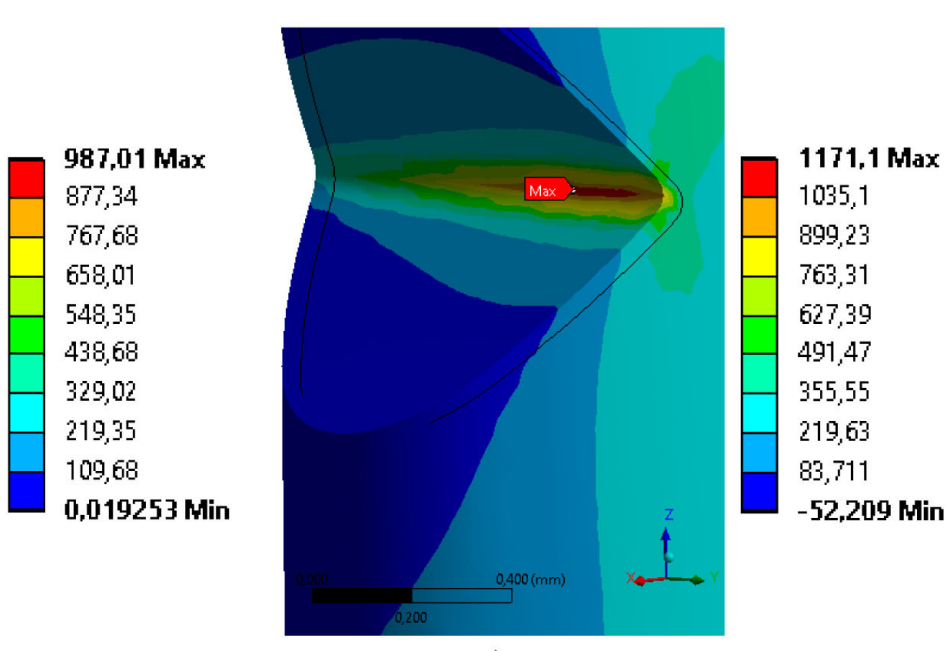

a)

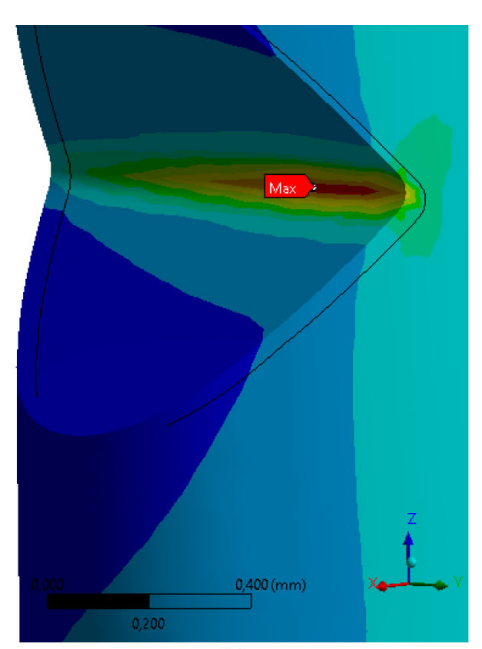

b)

Fig. 4. Distribution of the equivalent stress $\sigma_{\text {eqv }}$ (a) and the principal stress $\sigma_{1}$ (b) near the notch, for the analyzed blade with the resonance amplitude of $\mathrm{A}=1.8 \mathrm{~mm}$. 
Table 3. Results of numerical fatigue analysis

\begin{tabular}{|c|c|c|c|c|}
\hline No. & $\begin{array}{l}\text { Fatigue } \\
\text { model of } \\
\text { material }\end{array}$ & $\begin{array}{l}\text { Hardening } \\
\text { model }\end{array}$ & $\begin{array}{c}\mathrm{N}_{\text {in }} \cdot 10^{3} \\
(\mathrm{~A}=1.5 \mathrm{~mm})\end{array}$ & $\begin{array}{l}\mathrm{N}_{\text {in }} \cdot 10^{3} \text { (for } \\
A=1.8 \mathrm{~mm})\end{array}$ \\
\hline 1. & Man & Manson & 11.16 & 4.55 \\
\hline 2. & Man4 & Manson & 2.59 & 1.16 \\
\hline 3. & Mit & Manson & 2.39 & 0.54 \\
\hline 4. & MM & Manson & 6.32 & 2.11 \\
\hline 5. & BS & Manson & 7.56 & 2.51 \\
\hline 6. & Ong & Manson & 7.14 & 1.44 \\
\hline 7. & $\mathrm{RF}$ & Manson & 1.52 & 0.53 \\
\hline 8. & Med & Manson & 7.1 & 2.55 \\
\hline 9. & Man & Fatemi & 11.16 & 4.55 \\
\hline 10. & Man4 & Fatemi & 7.46 & 2.73 \\
\hline 11. & Mit & Fatemi & 9.46 & 1.52 \\
\hline 12. & MM & Fatemi & 10.33 & 3.19 \\
\hline 13. & BS & Fatemi & 14.99 & 4.43 \\
\hline 14. & Ong & Fatemi & 54.72 & 5.86 \\
\hline 15. & $\mathrm{RF}$ & Fatemi & 2.28 & 0.75 \\
\hline 16. & Med & Fatemi & 13.35 & 4.32 \\
\hline 17. & Man & Xianxin & 8.52 & 3.39 \\
\hline 18. & Man4 & Xianxin & 7.5 & 2.93 \\
\hline 19. & Mit & Xianxin & 1.81 & 0.41 \\
\hline 20. & MM & Xianxin & 5.68 & 1.84 \\
\hline 21. & BS & Xianxin & 7.41 & 2.37 \\
\hline 22. & Ong & Xianxin & 9.17 & 1.66 \\
\hline 23. & RF & Xianxin & 1.43 & 0.49 \\
\hline 24. & Med & Xianxin & 7.68 & 2.64 \\
\hline 25. & \multicolumn{2}{|c|}{ Maximal Value } & 54.72 & 5.86 \\
\hline 26. & \multicolumn{2}{|c|}{ Average Value (AV) } & 9.04 & 2.46 \\
\hline 27. & \multicolumn{2}{|c|}{ Minimal Value } & 1.43 & 0.41 \\
\hline
\end{tabular}

increase in the vibration amplitude to the value of $\mathrm{A}=1.8 \mathrm{~mm}$ caused that the average value of the number of load cycles for crack initiation decreased to the value of Nin $=2.46 \cdot 10^{3}$ (nearly a 4 -fold fall). The highest Nin value also occurred for the Ong model with Fatemi hardening, while the lowest occurred using Mitchell model with Xianxin hardening. From the results obtained, it can be concluded that the maximum value of the number of cycles until crack initiation, with an increase in amplitude from $1.5 \mathrm{~mm}$ to $1.8 \mathrm{~mm}$, caused a nearly 10 -fold decrease.

\section{RESULTS OF EXPERIMENTAL INVESTIGATION}

The experimental part of the work, related to the initiation of the crack, was carried out using the Unholtz-Dickie UDCO-TA-250 vibrating system in the Turbomachinery Laboratory of the Rzeszow University of Technology. The blades were examined under resonant conditions with a constant amplitude of displacement. The vibration amplitude was measured using a POLYTEC PSV-H400 laser scanning vibrometer. The tests were carried out for two compressor blades from the PZL-10W engine. Three methods of crack detection were used to observe the microcrack initiation. The first is based on a change of resonant frequency and UV fluid observation, the second is based on thermography image and the last one is based on a special algorithm $[6,15]$.

In both cases, the V-notch was made by cutting the material, at a height of $3 \mathrm{~mm}$ from the blade foot (depth of the notch was equal to $0.5 \mathrm{~mm}$ and radius in the bottom equal to $0.05 \mathrm{~mm}$ ). The intensity of exertion, during tests, was $10 \mathrm{~g}(1 \mathrm{~g}$ equals gravitational acceleration, $9.81 \mathrm{~m} / \mathrm{s}^{2}$ ). The amplitude of displacements of the tip of the blade was equal to 1.5 or $1.8 \mathrm{~mm}$ (depending on the case of study). During the experimental research, only the first form of resonant vibrations was analyzed. The flexural vibrations cause the bending of the feather of the blade, resulting in fatigue of the blade material. After the specified number of cycles, the initiation of the crack was observed at the bottom of the notch.

The results of the experiment are summarized in Table 4. This table contains the information on the number of cycles necessary to initiate the crack. The determined number of cycles for crack initiation corresponds to the minimum fatigue crack length. The crack was detected when the minimum crack length of $0.2 \mathrm{~mm}$ was reached. The initiation of the fracture was observed using a microscope and a fluorescent fluid. The blade was put into resonance and several thousand load cycles were applied. The test was then stopped and the blade was checked for cracking. If the crack was not initiated, another series of load cycles was applied. This procedure was repeated until a crack was detected.

For the amplitude of resonance vibrations equal to $\mathrm{A}=1.5 \mathrm{~mm}$, the number of cycles to initiate a crack with a length of about $0.2 \mathrm{~mm}$ was over $\mathrm{N}_{\text {in }}=190 \cdot 10^{3}$. For a $20 \%$ higher amplitude $(\mathrm{A}=1.8 \mathrm{~mm})$, the number of cycles for crack initiation was $\mathrm{N}_{\text {in }}=12.9 \cdot 10^{3}$. An increase of $20 \%$ in amplitude resulted in a reduction of durability by nearly 15 times.

Table 4. Results of experimental fatigue analysis

\begin{tabular}{|c|c|c|}
\hline No. & Amplitude A, $\mathrm{mm}$ & $\mathrm{N}_{\text {in }} \cdot 10^{3}$ \\
\hline 1. & 1.5 & 190.3 \\
\hline 2. & 1.8 & 12.9 \\
\hline
\end{tabular}




\section{CONCLUSIONS}

The numerical fatigue analysis showed a large discrepancy in the results of the number of load cycles for fatigue crack initiation for a given load variant. The scatter in the results is observed: the smallest value is nearly 40 times lower than the largest one (for resonance amplitude $\mathrm{A}=1.5 \mathrm{~mm}$ ). In addition, numerical and experimental studies showed a high qualitative similarity of the impact of the increase in the resonance vibration amplitude on the values of the obtained numbers of load cycles for the initiation of a fatigue crack. In the examined cases of the notched blades, an increase in amplitude by $20 \%$ (from $1.5 \mathrm{~mm}$ to $1.8 \mathrm{~mm}$ ) causes a 4-fold decrease in fatigue life, as indicated in the numerical tests. The analysis of the results of experimental studies showed that the discussed increase in the vibration amplitude caused a nearly 15 -fold decrease in fatigue life. It is worth mentioning that the results of numerical fatigue analysis based on the Ong model (with Fatemi hardening) show that the increase in the vibration amplitude resulted in a nearly 10-fold decrease in fatigue life. At the same time, in the case of the results of the mentioned numerical fatigue analyses based on the Ong model, the number of load cycles for the initiation of fatigue crack are only 2-3 times smaller than the results of experimental tests.

It should be mentioned that one of the reasons for the differences in results may be inaccuracy (and inability to measure) in certain quantities characterizing the material. In addition, a high resonance frequency value increases the fatigue strength. The moment of fatigue crack detection also influences the results of experimental tests. For the presented experimental tests, the minimum length of fatigue crack was $a=0.2 \mathrm{~mm}$.

On the basis of the results obtained in this paper, the use of the Fatemi hardening model as well as the Ong or Baumel-Seeger fatigue model is recommended in the case of the numerical fatigue analysis of the compressor blade. The use of other fatigue and hardening models may result in a large error in the estimated fatigue life values. These models are useful for the fatigue analysis of aircraft engine compressor blades.

\section{Acknowledgment}

The research leading to these results was co-financed from funds for the statutory activity of Department of Aircrafts and Aircraft
Engines, Rzeszow University of Technology (DS.ML.19.001) and also the Fulbright Program (sponsored by U.S. Department of State).

\section{REFERENCES}

1. Browell R. and Hancq A. Calculating and Displaying Fatigue Results. ANSYS Inc., 2006.

2. Chengzong L., Zhiyong Z., Xin C. and Yuanxiao S. Low-Cycle Fatigue Analysis and Experiment of Steel Specimens with Stress Concentration. Journal of Applicatied Mechanics, 17(3), 2000, 107-110.

3. Dowling N.E. Mean Stress Effects in Stress-Life and Strain-Life Fatigue. Blackburg: Virginia Polytechnic Institute and State University, F2004/51, 2004.

4. Hunecke K. Jet Engine: Fundamentals of theory, design and operation. Airlife Publishing, England, 2014.

5. Jakubowski R. Evaluation of performance properties of two combustor turbofan engine; Eksploatacja i Niezawodność 17(4), 2015, 575-581.

6. Lichoń D. and Bednarz A. The study on algorithm for identification the fatigue crack length of compressor blade based on amplitude-frequency resonant characteristics. Journal of Kones 24, 2017, 156-164.

7. Meggiolaro M.A. and Castro J.T.P. Statistical evaluation of strain-life fatigue crack initiation predictions. International Journal of Fatigue, 26, 2004, 463-476.

8. Mazurek P. Fatigue Strength of Thin-Walled Rectangular Elements in the State of Post-Critical Deformation. Advances in Science and Technology Research Journal,13(2), 2019, 84-91.

9. Mihaliková M., LiškováA., Vojtko M. and Kvačkaj T. Research of fatigue and mechanical properties AlMg$1 \mathrm{SiCu}$ aluminium alloys. Advances in Science and Technology Research Journal, 9(28), 2015, 56-60.

10. Nakhodchi S. and Salimpour M.E. Fatigue life prediction in damaged and un-damaged compressor blades. Engineering Solid Mechanics, 2, 2013, 43-50.

11. Neimitz A., Galkiewicz J., Lipiec S. and Dzioba I. Estimation of the Onset of Crack Growth in Ductile Materials. Materials 10, 2018.

12. Puchała K., Szymczyk E., and Jachimowicz J. Modelowanie laminatów w praktyce inżynierskie. Przegląd Mechaniczny 3, 2019, 29-34.

13. Stephens R.I., Fatemi A., Stephens R.R. and Fuchs H.O. Metal Fatigue in Engineering. John Wiley\& Sons, Ottawa, Canada, 2000.

14. Witek L. Numerical stress and crack initiation analysis of the compressor blades after foreign object damage subjected to high-cycle fatigue. Engineering Failure Analysis, 18, 2011, 2111-2125.

15. Witek L., Bednarz A. and Stachowicz F. Fatigue analysis of compressor blade with preliminary defect. Engineering Failure Analysis 58, 2015, 229-237. 